\title{
Planning for Water and Sanitation Facilities in an Emergency - A Case Study
}

\section{M.P.P.Dhanaseela and T.Ono}

\begin{abstract}
An appropriate response to an emergency depends on whether the emergency affects people where they live such as in the case of natural disaster or whether the population is displaced as a result of other pressures such as famine or war. Although the measures may differ, planning considerations for water supply and sanitation are similar in both situations.
\end{abstract}

This paper concentrates on the guidelines available for water and sanitation provisions in an emergency and the localized approach in a real situation. The actual scenario of planning, designing and implementation of water and sanitation facilities in an emergency camp for internally displaced people due to war is described. The case study focused on the block number 3 of Manic Farm Zone 3 (Arunachalam relief village) in Vavuniya district, Sri Lanka.

Important lessons learnt are shared in the article.

Keywords: water and sanitation, cluster, coordination, guidelines

\section{Introduction}

Water and sanitation (WatSan) are critical determinants for survival in the initial stages of a disaster. Disaster can be a natural such as earth quake, floods, landslides, tsunami etc or man made as war. People affected by disasters are more susceptible to illness and death from disease, which are related to inadequate sanitation, inadequate water supplies and poor hygiene.

Due to the heavy fighting between Government of Sri Lanka (GoSL) and Liberation Tigers of Tamil Eelam (LTTE) it was anticipated a huge flee from the battle area. Initially all the internally displaced people (IDP) flew from Vanni were housed in communal places such as schools, Technical colleges etc in Vavuniya.

Urgent need was arisen to find new locations for hosting the anticipated influx of IDPs. GoSL started to set up relief villages in Vavuniya district. Kathirakamar village or "Manic Farm Zone 0" (MF0), Anandakumaraswamy village or "Manic Farm Zone 1" were started to set up by GoSL. Meanwhile GoSL requested assistance from humanitarian agencies to set up "Manic Farm Zone 3" (MF3) or Arunachalam relief village. (Fig 1)
Initially, about 40 acre land of MF3 was cleared by the GoSL and it was sub divided in to 10 acre plots with internal and peripheral road network.

Due to lack of WatSan facilities during an emergency there is a serious, often sudden, threat to the health of the affected community which has great difficulty in coping without external assistance.

In general, steps were taken to assess the needs on food, shelter, medical aid, providing clean water and sanitation as they are the highest priorities in the event of an emergency.

\section{Common "Water supply" and Sanitation" situation in an emergency}

"Water" is a human right [5]. This right is recognized in international legal instruments and it provides sufficient, safe, acceptable,

\footnotetext{
Eng. (Mrs.) M.P.P.Dhanaseela, AMIE (Sri Lanka), B.Sc. Eng. (Hons) (Peradeniya), P.C..Dip. in Environmental water resources Eng \& Mgt., M.Eng. (AIT), Water and Santation Engineer, Engincering Div., International Organization for Migration.Sri Lanka.

Dr.T.Ono, Head of Engineering, Engineering Div., International Organization for Migration, Sri Lanka
} 


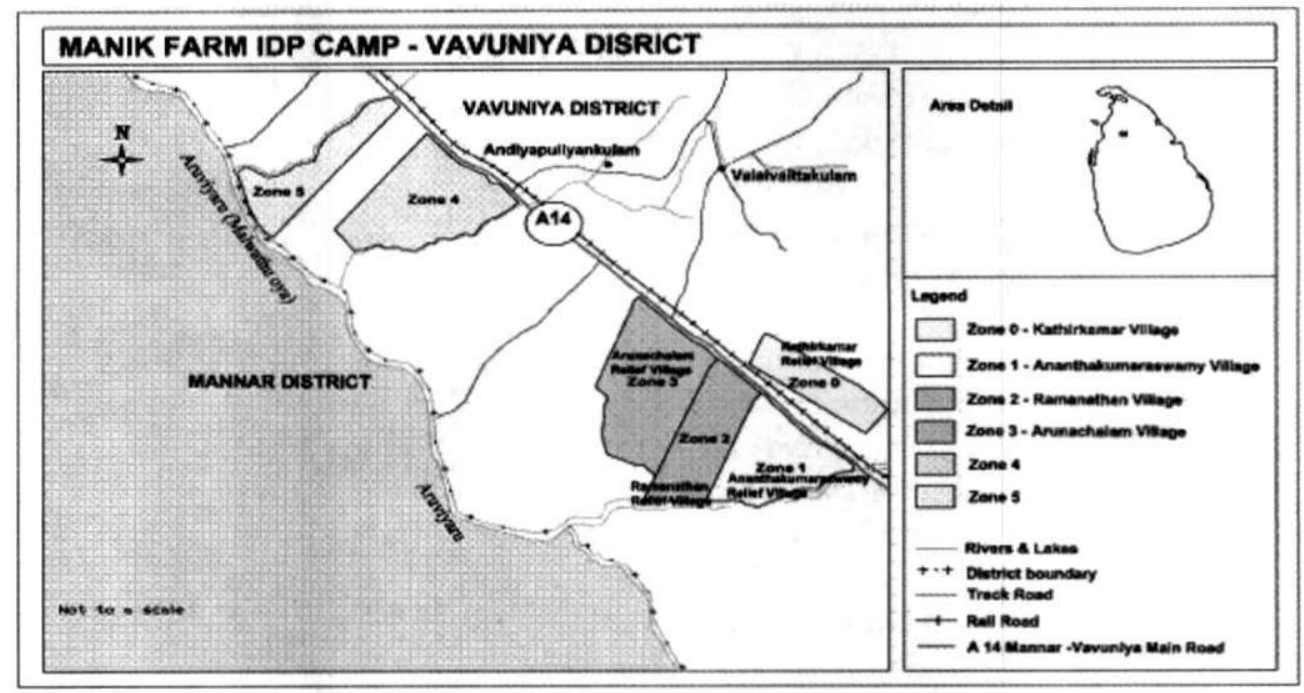

Fig 1- Manic Farm IDP camps layout

physically accessible and affordable water for personal and domestic uses. An adequate amount of safe water is necessary to prevent death from dehydration, to reduce the risk of waterrelated disease and to provide for consumption, cooking, and personal and domestic hygienic requirements.

The "Sanitation" is defined as the means of collecting and disposing of excreta and community liquid wastes in a hygienic way so as not to endanger the health of individuals and the community as a whole. (WHO, 1987)

Water and sanitation are critical determinants for human survival and dignity immediately after and during the initial stages of a disaster. These people are rights-holders just as everyone else, which means that States, as well as the international community have responsibilities towards them.

It is inevitable to have necessary planning procedures for ensuring at least minimum standard levels of water supply and sanitation as well as food, shelter and medical aid as usually are the highest priorities in the event of an emergency.

Water supply should be considered alongside immediate sanitation measures, however, which are just as important in controlling many

of the most common diseases found in disaster situations; Such as Hepatitis, Dysentery, Chickenpox, Dengue, Typhoid, Mumps and Diarrhoea in this case.
Sanitation is usually allocated a much lower propriety than clean water, but it is just as important in the control of many of the most common diseases found in refugee camps [3]. This situation was understood and emphasis was given to sanitation as well as water in this case.

"Sanitation", throughout the paper, refers to excreta disposal and solid waste disposal.

\section{Study Area}

The actual scenario of planning, designing and implementation of water and sanitation facilities in the block3 of "Manic Farm Zone 3" (MF3) or Arunachalam relief village in Vavuniya district, Sri Lanka is described. (figure 2).Extent of the area is about 10 acres.

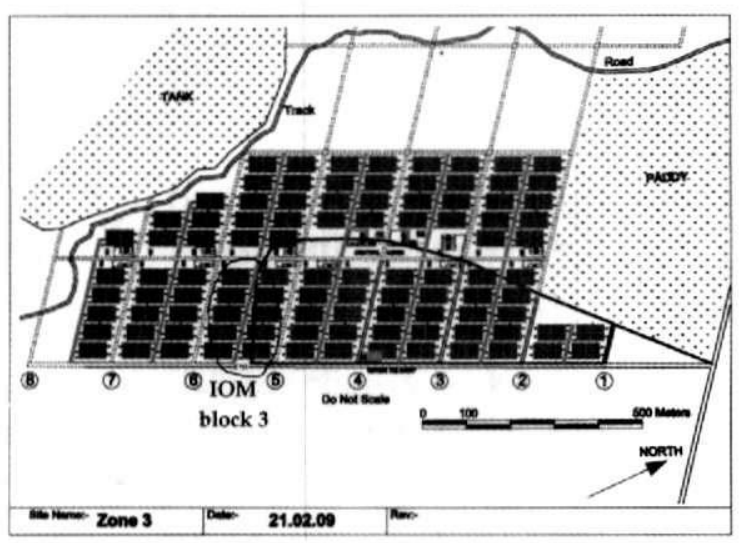

Fig 2- Block No 3 of MF3 


\section{Coordination mechanism}

Coordination mechanism with the humanitarian organizations that extended their wiliness to assist IDPs was taken place in the Vavuniva field level as well as Colombo country level. Shelter cluster comprises of agencies involve in shelter construction and it is led by the United Nation High Commissioner for Refugees (UNHCR) where as the Water Sanitation and Hygiene cluster (WASH cluster) comprises of agencies which have the capacity of provision of water and sanitation facilities and it is led by the United Nations Children's Fund (UNICEF). Other than those mentioned, there were several clusters formed to assist the IDPs in several ways. Regular inter-agency meetings were held and they were open to relevant government personnel.

It was agreed by each agency that WASH cluster follow shelter cluster decision. It means in general, a place where an agency build shelters should be responsible for implementation of WatSan facilities. Those who do not implement WatSan facilities can be supported by other agencies that have the capacity.

Depending on the stocks availability, Shelter cluster decided to allocate 10 acre block to United Nations Office for Projects Services (UNOPS), Solidar, and International Organization for Migration (IOM) and Norwegian Refugee Council (NRC).

A typical block plan was drawn with the agreement of clusters (fig 3 ). Each 10 acre block was divided in to two units by means of an internal road. All the WatSan facilities were planned to construct adjacent to roads. Shelter were planned to build in the middle of the units.

\section{Minimum standard levels and guidelines on water and sanitation in an emergency}

Emergency response planning is vital for catering at least minimum standard levels of water and sanitation requirements.

Water and sanitation facilitation in the relief village was largely based on the Sphere project (2004) minimum standards in water supply and sanitation. The sphere project is the product of

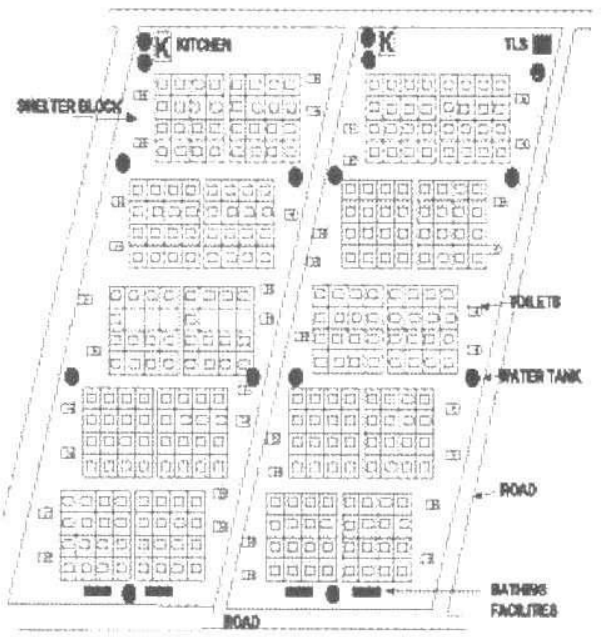

Fig 3 - Typical Block plan

international inter-agency collaboration and its aim is to improve the quality of assistance provided to people affected by disasters and to enhance the accountability of the humanitarian system in disaster response.

The minimum standards describe what people should have as a minimum for their health and dignity. Agencies should target minimum standard WatSan facilities but must strive to do better wherever possible.

All the disaster affected people must have the access to all the WatSan facilities. Care should be given to vulnerable people; pregnant women, children, older people, disabled people etc.

Standards for Water supply [8].

- Each person needs 5 liters of drinking water a day to survive. For the best optimal health, each person should have a total of 15 liters a day so they can cook and wash also.

A guide for assessing the demand for water in a disaster situation (Basic survival water) can be state as follows,

1. Survival need; water intake minimum 2.5-3 LPCD

2. Basic hygiene practise : $2-6 \mathrm{LPCD}$

3. Basic cooking needs: 3-6LPCD

- Maximum distance to household to the nearest water point is 500 meters 
- Maximum number of people per different type water source is as follows,

1. 250 people per tap based on a flow of 7.5 litres/minute

2. 500 people per hand pump based on a flow of 16.6 litres/minute

3. 400 people per well based on a flow of 12.5 litres/minute

- Queuing time at a water source is no more than 15 minutes

- It takes no more than three minutes to fill a 20 litre container

- Each house hold has two water collecting containers of 10-20 litres

- Sufficient and separate bathing cubicles for males and females

Standards for Sanitation [8].

- A maximum 20 people use each toilet.

- Separate toilets for men and women

- Toilets are no more than $50 \mathrm{~m}$ from shelters

- Pit of the toilet should be at least $30 \mathrm{~m}$ from water source

- All shelter have access to a refuse container and it should no more than $100 \mathrm{~m}$ away from the shelter

- At least 100 liter refuse container is available per 10 families where domestic refuse is not buried on-site

- All toilets should be provided water for anal cleansing and flushing

A guide for assessing the demand for water for basic hygiene practice in a disaster situation can be stated as follows,

1. water for anal washing: 1-2L/person/day

2. water for flushing toilets: 3-5L/user/day

Adjustments made to the minimum standard with respect to Sri Lankan context are given under "monitoring phase".
Although the guidelines do not specify a ratio of toilets for disable people, WASH cluster agreed to provide 1:10 ratio of toilets for normal to disable at the initial stage and later to raise it up to 1:20 depending on the site assessments.

\section{Planning and Implementation}

An appropriate response to an emergency depends on whether the emergency affects people where they live such as in the case of natural disaster or whether the population is displaced as a result of other pressures such as famine or war. Although the measures may differ, planning considerations for water supply and sanitation are similar in both situations.

Demand assessment, location and protection of water sources, water quality, water distribution, collection and storage of water, garbage and septage disposal are the basic planning considerations which must be addressed as soon as an emergency occurs.

IOM started its plotting on 24 February 2009 and started constructing Shelters in the 10 acre, Block number 3 (Block 3 ) of MF3 on 25 February.

294 emergency shelters were put up in the block 3 of MF3 according to

- the UNHCR guidelines for shelters. i.e. Minimum surface area per person excluding garden space should not be less than $30 \mathrm{~m} 2$ per person.

- Typical block plan

- Actual land availability with respect to existing trees/low lying areas etc

It was assumed that each shelter is given to an individual family and house hold size is of five.

As such all the WatSan facilities were planned targeting the total of 1470 IDPs.

Toilets designs were discussed at Technical working group in WASH cluster- Vavuniya. Following the discussions, IOM, UNOPS, Oxfam and Solidar were requested to build models of Emergency toilet at MF3 and those models are reviewed by PHI (Public Health Inspector). IOM's toilet design was recommended. 
It consisted of two toilet cubicles with soakage pit. Super structure of the toilets was timber frame with corrugated galvanized iron sheets and substructure is of timber planks. Internal dimension of the singie toilet was $3^{\prime} \times 4^{\prime}$ and the heights of front and rear sides of the toilet were $6^{\prime} 8^{\prime \prime}$ and $6^{\prime} 2^{\prime \prime}$. Dimensions of the timber pit were $5^{\prime} \times 5^{\prime} \times 4^{\prime}$ (Figure 4). Toilet pit design out of plywood sheets was not approved. 37 sets of toilets $(1470 / 20=74$ numbers of toilets were planed to construct in the block).

Toilets were segregated by sex. It was assumed number of men to women ratio to be 1:1 and 1:1 ratio toilets was targeted at men to women.

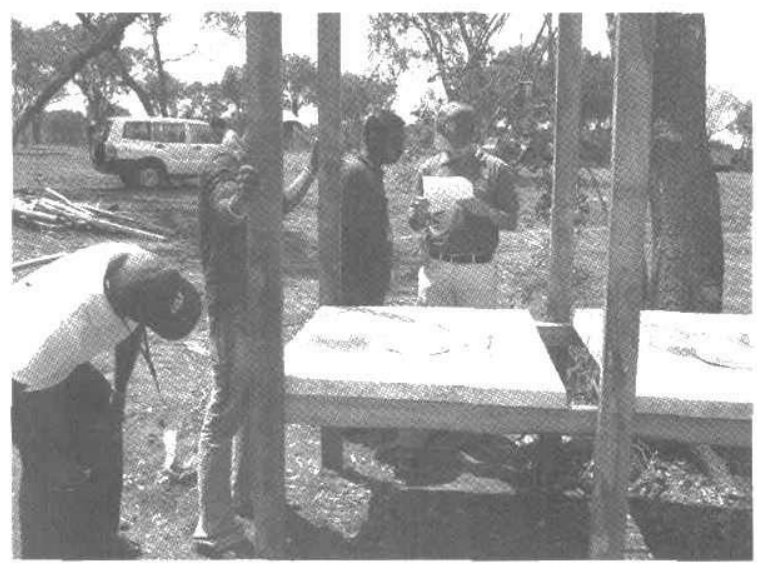

Fig 3-IOM Emergency Toilet superstructure

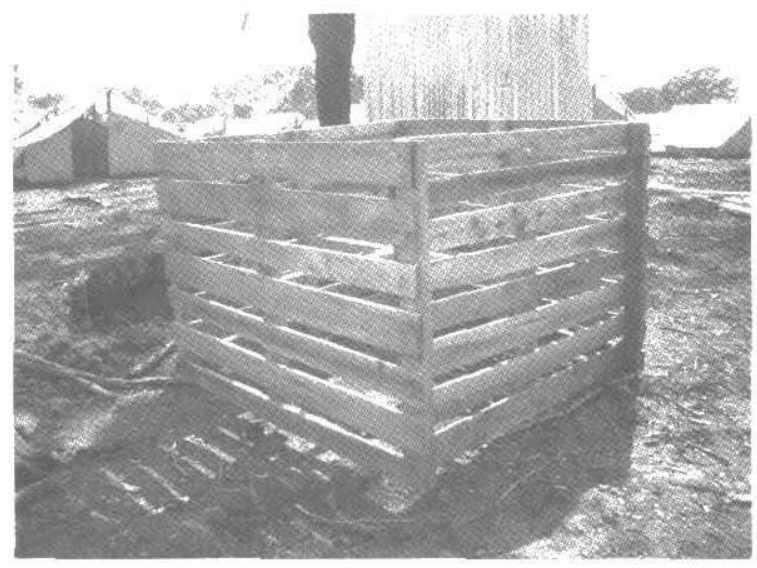

Fig 4- IOM Emergency Toilet pit

For 16 shelters two sets of toilets were constructed and one set of toilet was targeted to men and other set for women. To provide the degree of privacy, a 6 ' high screen out of timber frame and tarpaulin sheet was built in front of women's toilet. (Figure 5)

According to the Sri Lankan cultural context, the anal cleansing is with water. On the other hand water should be available for flushing toilets and hand washing after defecation. For these purposes, a $1000 \mathrm{~L}$ tank with two taps on the $3^{\prime}$ height steel stand was placed.

Toilets for disable were constructed with bigger internal dimensions $\left(3^{\prime} \times 5^{\prime}\right)$, ramp with 1:6 slope and hand rails etc

In order to prevent over flowing of toilet pits, it was suggested to gully sucked at frequent intervals, an average once in 2 to 3 week's time.

Normal practice in the initial stage of an emergency is to supply all water of a quality

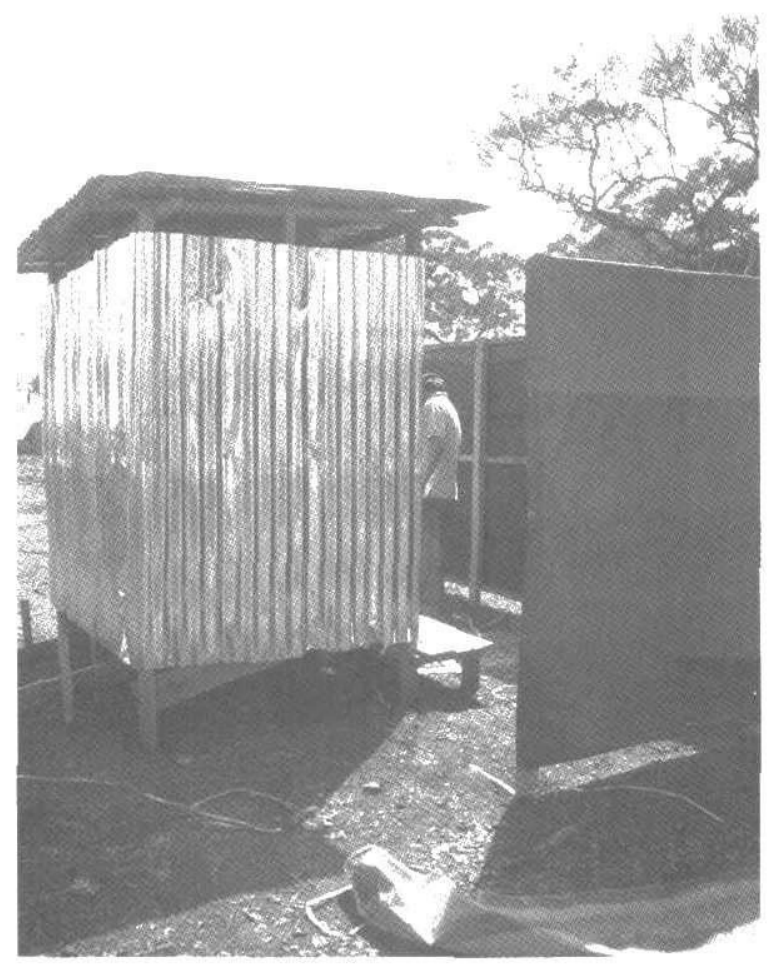

Fig 5 - Toilet with privacy screen for women

suitable for drinking. Treating water to this standard is often takes time. Some agencies were in the process of purchasing portable water treatment plants targeting to provide treated water.

As an immediate measure, supply of good quality water from distance sources was possible by means of water tankers. WASH cluster members started to procure and hire water tankers to support the bowser fleet of the government authorities in Vavuniva. 
As a precaution to ensure that water is bacteriological safe, it should be disinfected. Chlorination technique with High Test Hypochlorite granules, Bleaching powder etc. was adopted after carrying out the Jar test and to maintain $0.2-0.5 \mathrm{mg} / \mathrm{L}$ chlorine residual at point of consumption. It was planned to distribute chlorinated water from tankers to water points. Water collection point was comprised with 1000 liter tank with two taps place on the $3^{\prime}$ height steel stand.

Assuming 10L/user/day, fourteen numbers of water points were installed in the block.

There is possibility of contamination of water after the water has been collected from the supply. It is necessary, therefore to provide water collection and storage vessels that are easy to use and keep clean. Two numbers of Jerry cans were given to each family.

It was assumed that the drinking Water to be a crucial issue in IDP sites. National Water Supply and Drainage Board (NWSDB) started drilling tube wells.

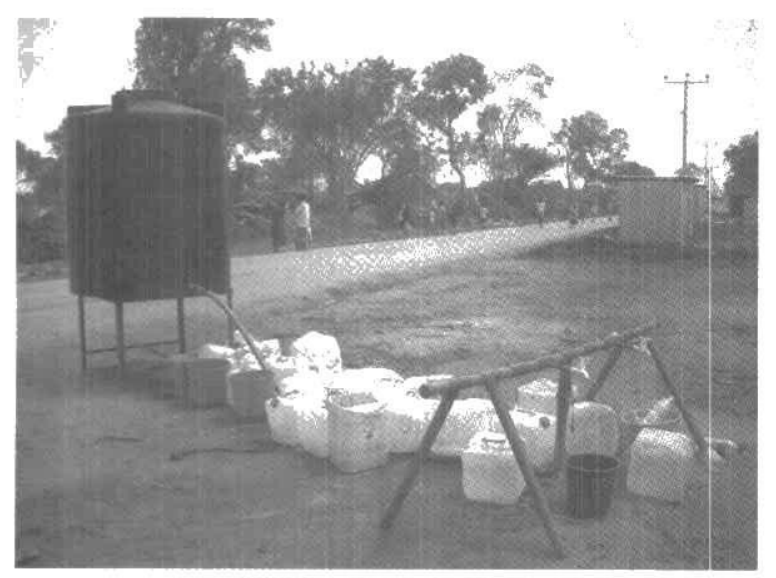

Fig 6- A water point

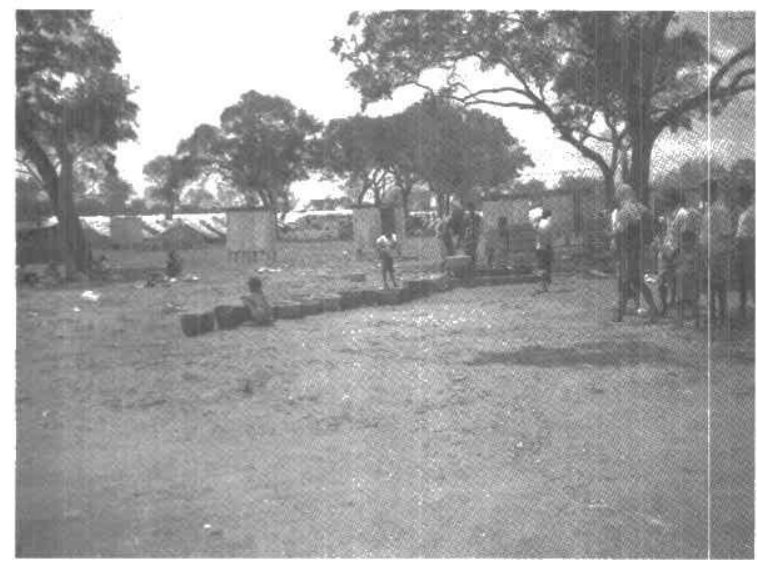

Fig 7-A tube well in operation
Three tube wells were constructed in the block. At that time NWSDB in Vavunia believed that groundwater capacity might be limited and suggested that boreholes mav provide sufficient water for drinking purposes only. Their plans were to supplement this (potential) drinking groundwater supply with surface water piped from Malwathu ova. Till such time NWSDB to install the above systems, it has been recognized that temporary water storage and distribution facilities will need to be installed on site and water bowsered to fill these tanks. A $95 \mathrm{~m} 3$ tank was installed for this purpose.

After providing the toilet and drinking water facilities, construction of bathing areas was took place.

People must have a space where they can bathe in privacy and dignity. Since the discussions to lay a water pipe line from Malwathu oya to MF3 initiated, during this period all the bathing areas were designed to have pipe network which can be connected to the planned water line. It was planned to install water tanks near the two bathing areas till they are connected to the proposed water pipe line.

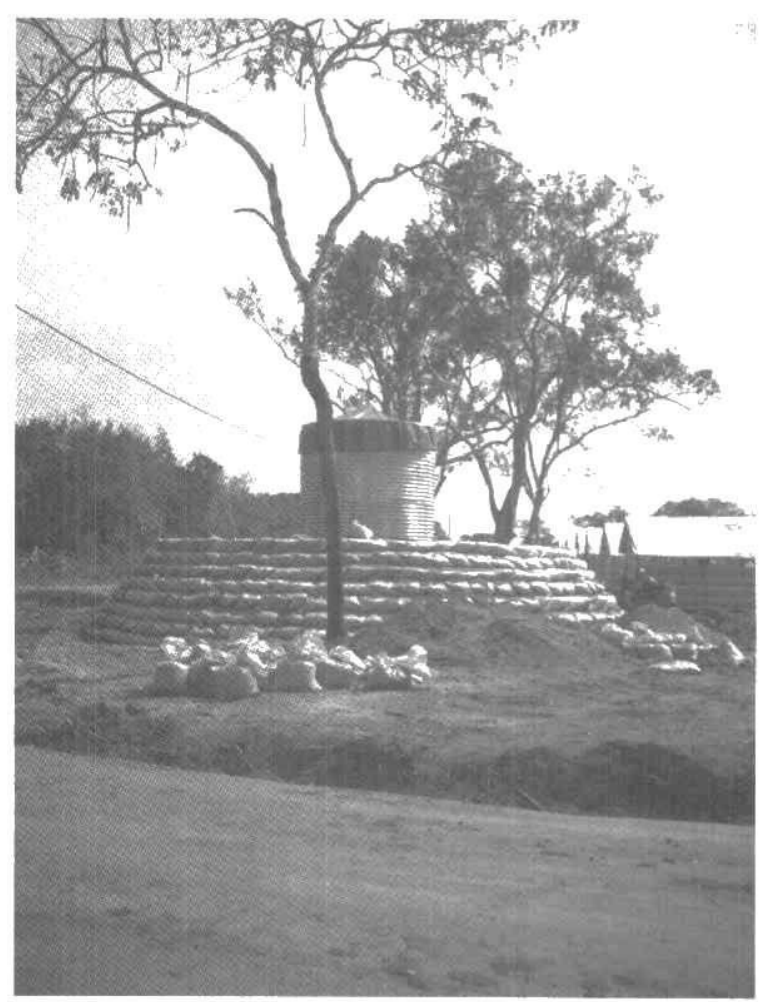

Fig 8-Common water storage tank in block 1 
Four bathing areas were constructed in the block. Two of them were for men and other two for women. Area of a bathing area was $18^{\prime} \times 12^{\prime}$ (Fig 9). Assuming that children have bathing with women and washing is done mainly by women, 10 taps were installed inside the women's bathing area whereas 8 taps were installed inside the men's bathing area.

It is essential to dispose solid waste generated inside the camp so as to minimize the risk arising from flies and unhealthy environment. It was planned to collect solid wastes from individual shelters to a common bin and then they were collected and transported to a dumping site by the government authority.

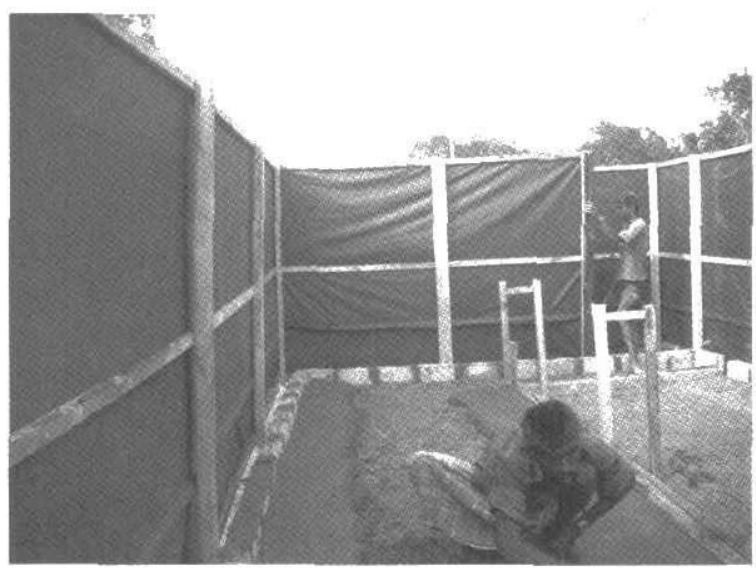

Fig 9- Construction of a bathing facility

WASH cluster members started to procure and hire tracters to support the tractor fleet of the government authorities in Vavuniya.

A 100 litre garbage bin was placed in the middle of 10 shelters. All together 30 numbers of garbage bins were place in the block.

\section{Monitoring phase}

IDPs stated to occupy the shelter in the block in March 2009. Total of 1382 IDPs hosted in the block.

Though the WatSan facilities were designed and provided in according to the above minimum standards, it was evident that the water quantity was not sufficient. About $10 \mathrm{~L} /$ person/day treated water and total of about $25 \mathrm{~L} /$ person/ day water was tried to supply.
Some problems arise just after arrival of IDPs;

- Some toilets were blocked due to nonflushing

- Some water points were not filled frequently

- Chlorinated water was used for bathing and untreated water used for drinking purposes by IDPs without paying much attention

- Some of the garbage bins were taken by the IDPs for cloth washing purposes

- Garbage were scattered

- Accessibility to the internal road of the block for vehicles were not given

A coordination mechanism was set up to provide remedial actions.

Volunteers were selected from the IDPs they were trained to inform the camp managers about site condition; such as inform about over flowing pits, blockages of toilets, bowser function etc. Camp managers coordinate with WASH cluster and relevant GoSL authorities for immediate action.

Volunteer groups were provided with tools and materials for maintaining and cleaning the toilets.

For security reasons the access to the internal road of the block for vehicles was not given, all the water tanks adjacent to internal road were shifted near to main roads which were given the accessibility. All the toilets near the internal road were decommissioned.

Same methodology was practiced for providing WatSan facilities to entire MF3.

It was evident that simply providing sufficient water and sanitation facilities does not ensure their optimal use or impact on public health.

Percentages of children in MF3 suffered from diarrhea, scabies and other skin diseases as of 1330 the May 2009 are 39.9, 2.4 and 7.7 respectively. [4] 
Table 1- cumulative number of cases reported duting $1^{\text {st }}$ June to 28th August 2009.[1]

\begin{tabular}{|l|c|}
\hline Description & $\begin{array}{c}\text { Cumulative total cases } \\
\text { reported in MF3 }\end{array}$ \\
\hline Hepatitis & 885 \\
\hline Dysentery & 247 \\
\hline Diarrhea & 3205 \\
\hline
\end{tabular}

\section{Conclusions}

It was evident that the coordination mechanism among WASH cluster, GoSL authorities and Volunteers from the IDPs made a great success in WatSan facilitation.

Agency staff should establish key contacts within such organizations and ensure that regular consultation occurs.

It is essential to get the proposed site layouts and designs endorsed by GoSL authorities before start implementation.

Socio-cultural factors must be considered. Existing perceptions, beliefs and practices have to be taken into consideration when selecting technology.

In order to achieve the maximum benefit from the response it is imperative to ensure that disaster affected people have the necessary information knowledge and understanding to prevent water and sanitation related disease. They must be educated to use toilets in the most hygienic way and infant's faeces are disposed of immediately and hygienically, to wash their hand after defecation and before eating and food preparation etc.

Even though those observations were made in the block 3 this time, authors believe that most of planning and design criteria would be applicable to other emergency camp set up.

\section{References}

1. Communicable disease weekly update: No 9, Epidemiology unit Cheddikulam coordination centre, Vavuniya \& cheddikuan MOH office, Ministry of health

2. David,J and Lambert,R., Engineering in Emergencies: A practicle guide for relief workers,IT publication, London,1995

3. Emergency sanitation in refugee camps,24 th WEDC conference-Islamabad, Pakistan,1998,S. Baghri and R.A.Reed

4. Jayatissa R.,Presentation slide on Rapid assessment of Nutitional staus among post war displaces population in Vanuniya ,June 2009.

5. The Right to Water (article 11 and 12 of the International Covenant on Economic, Social and Cultural Rights,CESCR General Comment 15, 26 November 2002, U.N.Doc. E/C.12/2002/11,Conmittee on Economic, Social and Cultural Rights.

6. Planning and management of emergency sanitation,Procedingts of an international conference, WEDC, Loughbough University, UK,10th-12th April 2002.Edited by Sam Treglown,Peter Harvey and Bob Reed

7. Peter, H., Bob,R., Emergency sanitation, Assement and programme design, Water, Engineering and development center,WEDC Loughborough University, 2002.

8. Sphere project: humanitarian charter and minimum standard in disaster response, 2004 edition

9. Water and Sanitation cluster-Vavuniya/ Colombo meeting minutes 